\title{
Demanda de tração, mobilização de solo na linha de semeadura e rendimento da soja, em plantio direto
}

\author{
Osmar Conte(1), Renato Levien(1), Carlos Ricardo Trein ${ }^{(1)}$, Antônio Alexandre Petersen Xavier ${ }^{(1)}$ \\ e Henrique Debiasi ${ }^{(2)}$
}

(1)Universidade Federal do Rio Grande do Sul, Faculdade de Agronomia, Departamento de Solos, Avenida Bento Gonçalves, no 7712 ,
CEP 91540-000 Porto Alegre, RS. E-mail: agriconte@gmail.com, renatole@ufrgs.br, trein@ufrgs.br, alexandrepexavier@hotmail.com
(2)Embrapa Soja, Rodovia Carlos João Strass, Distrito de Warta, Caixa Postal 231, CEP 86001-970 Londrina, PR. E-mail: debiasi@cnpso.embrapa.br

Resumo - O objetivo deste trabalho foi avaliar a relação entre a força de tração (FT) na haste sulcadora de adubo e o volume de solo mobilizado na linha de semeadura em função da quantidade de resíduos, do tráfego de rodados de trator e da profundidade de sulcamento, e sua influência sobre a performance agronômica da soja. Os tratamentos englobaram seis doses de resíduos culturais (DR), duas profundidades de trabalho das hastes sulcadoras (PT) e duas condições de tráfego - com e sem tráfego de rodados de trator -, em blocos ao acaso e parcelas subsubdivididas. Os tratamentos foram aplicados com e sem irrigação, em Argissolo Vermelho, sob plantio direto. As diferentes PT e condições de tráfego influenciaram significativamente a FT. Independentemente da condição de irrigação, as DR não influenciaram a produtividade de grãos e a massa seca da parte aérea da soja. Sem irrigação, a produtividade da soja aumentou em $180 \mathrm{~kg} \mathrm{ha}^{-1}$ quando a PT passou de 0,064 para $0,10 \mathrm{~m}$, o que demonstra que a aplicação do fertilizante a profundidades maiores é uma prática viável para diminuir os efeitos da seca sobre a cultura.

Termos para indexação: Avena strigosa, Glycine max, doses de resíduo, força de tração, semeadora de precisão.

\section{Draft power requirement, soil mobilization in sowing lines and soybean yield in no-tillage}

\begin{abstract}
The objective of this work was to evaluate the relationship between the draft power (FT) in the fertilizer furrow-opener and the volume of mobilized soil in the sowing line as affected by the amount of residues, tractor traffic and furrow-opening working depth, and its influence on soybean agronomic performance. Treatments consisted of six residue dosages (DR), two fertilizer furrow-opener working depths (PT) and two soil traffic conditions - with and without tractor traffic - carried out in a randomized block design, in a split-split-plot scheme. The treatments were applied with or without irrigation under no-tillage on a Rhodic Paleudult soil. The different PT and tractor traffic conditions influenced FT significantly. Regardless of the irrigation conditions, DR treatments did not affect soybean grain yield and shoot dry matter weight. In the absence of irrigation, soybean productivity increased by $180 \mathrm{~kg} \mathrm{ha}^{-1}$ when PT was changed from 0,064 to $0,10 \mathrm{~m}$, which indicates fertilizer furrow-opener at greater depths as a viable practice to decrease the effects of drought on crop.
\end{abstract}

Index terms: Avena strigosa, Glycine max, amount of residue, draft power, precision seeders.

\section{Introdução}

No sistema de plantio direto, o tráfego de maquinário agrícola é reduzido, em relação ao sistema de preparo convencional, mas também pode influenciar as propriedades dos solos, ainda que apenas as operações de semeadura e colheita sejam realizadas, já que os rodados dos tratores e colheitadeiras têm grande potencial de compactação do solo em superfície e subsuperfície (Schuler \& Wood, 1992). Solos mais compactados aumentam o desempenho de tração dos pneus, mas requerem mais esforço para serem mobilizados, aumentam o desgaste de máquinas e equipamentos e podem prejudicar ou mesmo impedir o desenvolvimento radicular das plantas (Silva et al., 2000) e torná-las, assim, mais suscetíveis a perdas de produtividade em condições de deficiência hídrica (Beutler et al., 2005).

No caso de semeadoras-adubadoras, o maior esforço de tração pode resultar, também, do aumento na profundidade de atuação dos órgãos ativos, especialmente discos de corte de resíduo e sulcadores

Pesq. agropec. bras., Brasília, v.44, n.10, p.1254-1261, out. 2009 
para abertura de sulcos de adubação e semeadura (American Society of Agricultural Engineers, 1999). Mello et al. (2003) verificaram que o mecanismo de haste sulcadora apresentou maior capacidade de mobilizar o solo, e provocou reduções na sua densidade e resistência à penetração, bem como aumento da macroporosidade. De acordo com esses autores, o uso da haste sulcadora promove acréscimo de $11,3 \%$ na produtividade do milho em relação à obtida com uso de sulcador de discos. Koakoski et al. (2007) constataram essas mesmas informações para as variáveis de solo e demonstraram, ainda, que a pressão das rodas compactadoras melhora a eficiência de germinação quando há uso de hastes sulcadoras. $\mathrm{O}$ uso de disco de corte de palha e sulcadores do tipo facão, apesar de permitir operar em superfície com cerca de $8 \mathrm{Mg} \mathrm{ha}^{-1}$ de resíduos, resulta em exposição de cerca de $40 \%$ da superfície de solo, em razão, principalmente, do solo expulso do sulco (Aratani et al., 2006).

Embora a deficiência hídrica durante o período reprodutivo ocasione as maiores reduções na produtividade da soja, a deficiência de água durante o período vegetativo também é prejudicial, por afetar a absorção de nutrientes, a produção de área foliar, diminuir a capacidade fotossintética da planta, e a produção de matéria seca (Bonato, 2000). A deficiência hídrica submete a planta de soja a um estresse que se manifesta na forma de estatura baixa, folhas pequenas e murchas, entrenós curtos, redução na taxa de crescimento da cultura, menor índice de área foliar, menor taxa de expansão foliar, menor duração da área foliar, atividade fotossintética menos intensa, prejuízos à fixação de nitrogênio e, por influir no metabolismo geral da planta, afeta negativamente a produtividade de grãos (Desclaux et al., 2000; Neumaier et al., 2000). A estiagem durante o período reprodutivo causa reduções na produtividade de grãos em razão do aborto de flores e de legumes, da diminuição no número de grãos por legume e do enchimento de grãos (Desclaux et al., 2000; Neumaier et al., 2000). A disponibilidade hídrica no estádio R5 é considerada crítica para a soja, já que nesse estádio ocorre grande translocação de reservas para enchimento dos grãos e a absorção de nutrientes do solo e a fixação biológica do $\mathrm{N}$ continuam sendo necessárias (Bonato, 2000).

O objetivo deste trabalho foi avaliar a relação entre a força de tração (FT) na haste sulcadora de adubo e o volume de solo mobilizado na linha de semeadura em função da quantidade de resíduos, do tráfego de rodados de trator e da profundidade de sulcamento, na presença e ausência de irrigação e sua influência sobre a performance agronômica da soja.

\section{Material e Métodos}

O experimento foi conduzido na Estação Experimental Agronômica da Universidade Federal do Rio Grande do Sul $\left(30^{\circ} 05^{\prime} \mathrm{S}, 51^{\circ} 40^{\prime} \mathrm{W}\right.$, com altitude média de $46 \mathrm{~m}$ ), localizada no Município de Eldorado do Sul, RS, região fisiográfica da Depressão Central. O solo, com textura superficial franco-argilo-arenosa e origem granítica, é atualmente classificado como Argissolo Vermelho distrófico típico e apresenta a seguinte distribuição granulométrica na camada de 0 a $20 \mathrm{~cm}$ : $400 \mathrm{~g} \mathrm{~kg}^{-1}$ de areia, $300 \mathrm{~g} \mathrm{~kg}^{-1}$ de silte e $300 \mathrm{~g} \mathrm{~kg}^{-1}$ de argila. O clima local é do tipo Cfa, subtropical úmido, segundo classificação de Köppen (Bergamaschi et al., 2003). O experimento foi conduzido em campo nativo que vem sendo cultivado há quatro anos em plantio direto, com culturas anuais de aveia-preta no inverno e de soja e milho no verão.

Odelineamento experimental foi o de blocos ao acaso, com parcelas subsubdivididas, com três repetições por tratamento, organizado da seguinte forma: seis doses de resíduos de aveia-preta $\left(0,2,3,4,5\right.$, e $\left.6 \mathrm{Mg} \mathrm{ha}^{-1}\right)$, como parcela principal; duas profundidades teóricas de atuação da haste sulcadora de adubo $(0,064$ e $0,12 \mathrm{~m})$, como subparcelas; e dois locais de atuação da haste sulcadora; linha sem tráfego e com tráfego de rodados do trator, como subsubparcelas. Foram realizados dois experimentos, um em condições irrigadas e outro em não irrigadas. As parcelas apresentaram as dimensões de 5,5 $\mathrm{m}$ de largura por $7 \mathrm{~m}$ de comprimento.

A cultura da aveia-preta (Avena strigosa Schreb.) foi implantada no outono e cultivada como cultura de cobertura de solo até a primavera, quando apresentou massa de matéria seca suficiente para atender à maior dose de resíduos proposta $\left(6 \mathrm{Mg} \mathrm{ha}^{-1}\right)$. Após atingir o ponto de maturação, a aveia-preta foi colhida mecanicamente, com uma colhedora de grãos. Durante a colheita, a palha proveniente do saca-palhas e peneiras da colhedora foi coletada em lona plástica e, após a pesagem da quantidade necessária em cada parcela, foi uniformemente distribuída, com a finalidade de obtenção das doses de resíduos na superfície do solo.

$\mathrm{Na}$ safra 2003/2004, foi utilizada a cultivar de soja BRS 137, recomendada para a região (Bonato

Pesq. agropec. bras., Brasília, v.44, n.10, p.1254-1261, out. 2009 
et al., 2001), com emprego de 52 sementes $\mathrm{m}^{-2}$, inoculadas com inoculante específico. A adubação foi realizada de acordo com a análise química do solo e as recomendações técnicas para o Rio Grande do Sul e Santa Catarina (Sociedade Brasileira de Ciência do Solo, 2004). A semeadura foi efetuada com a semeadora-adubadora de precisão, com cinco linhas espaçadas em 0,40 m. O sistema de abertura do sulco e de semeadura foi constituído por um disco de corte de palha, um sulcador tipo facão para deposição de adubo e um sistema de duplo disco para deposição de sementes. A profundidade de deposição de sementes foi regulada para $0,05 \mathrm{~m}$, enquanto a aplicação do fertilizante foi regulada para duas profundidades teóricas $(0,064$ e $0,120 \mathrm{~m}$ ), que resultaram em profundidades efetivas médias de trabalho de 0,064 e $0,100 \mathrm{~m}$, respectivamente. $\mathrm{O}$ trator utilizado para tracionar a semeadora-adubadora dispunha de tração dianteira auxiliar (TDA) e potência máxima de $53 \mathrm{~kW}$ no motor, com massa em ordem de marcha de 3,52 Mg, pneus traseiros 18.4-30 R1, pneus dianteiros 12.4-24 R1, com pressão de inflação de 95 e $110 \mathrm{kPa}$, respectivamente, e bitola de 1,65 m. $\mathrm{Na}$ semeadora, foram instrumentadas com sensores do tipo "strain gages" a haste da linha central e uma das extremidades, a qual coincidiu com os rastros dos pneus esquerdos do trator, a fim de mensurar a força de tração demandada. Como o tráfego nas parcelas experimentais é controlado, isto é, o trator trafega sempre nos mesmos locais, a haste sobre o rastro do pneu trabalhou em solo que já havia sofrido seis passagens dos rodados do trator, após a dessecação do campo nativo e utilização com culturas anuais. Os dados de esforço de tração foram obtidos por meio de um datalogger modelo CR23X, Campbell Scientific. Para determinar a área de solo mobilizado, utilizou-se um perfilômetro de varetas espaçadas em $0,01 \mathrm{~m}$.

A massa de matéria seca de raízes (MSR) de soja foi determinada em amostras de solo de até $0,12 \mathrm{~m}$ de profundidade na linha e na entrelinha e $0,20 \mathrm{~m}$ de distância da linha, obtidas com um trado calador de 0,065 m de diâmetro, quando a cultura encontrava-se no final do período reprodutivo, com três subamostras por parcela. Em laboratório, as amostras foram dispersas em água e passadas em peneira de $1 \mathrm{~mm}$, onde as raízes foram separadas e posteriormente secas em estufa a $65^{\circ} \mathrm{C}$ e pesadas.

O rendimento biológico $(\mathrm{RB})$ da cultura da soja foi representado pela quantidade de massa de matéria seca acumulada pela parte aérea da planta, e obtido pela soma da massa de matéria seca da parte vegetativa e dos grãos, na maturação fisiológica (estádio R8). $\mathrm{O}$ índice de colheita (IC) expressa a eficiência de translocação dos produtos da fotossíntese para as partes economicamente importantes da planta, consiste na razão entre a massa da matéria seca de grãos e o $\mathrm{RB}$, sendo expresso em percentagem. Para determinar a massa de matéria seca da parte aérea (MSPA), no momento da colheita foram pesadas todas as plantas de soja colhidas na parcela, composta pelas linhas de soja de cada tratamento. Os grãos foram posteriormente separados da palha, da qual uma amostra foi retirada e levada para a estufa, para determinação da massa seca a $65^{\circ} \mathrm{C}$. Para a obtenção dos componentes de rendimento da soja, foram tomadas dez plantas por parcela, obtidas aleatoriamente no total da amostra coletada para determinação da produtividade, usadas para contagem de legumes por planta, número de grãos por legume e determinação da massa de 100 grãos.

No experimento irrigado, realizou-se a irrigação na área experimental de forma suplementar, quando a pluviosidade era insuficiente ou não ocorreu, como aconteceu em boa parte do ciclo da soja neste experimento. O conjunto de irrigação usado, com motobomba e aspersores, possibilitava a aplicação de água a uma taxa de $15 \mathrm{~mm} \mathrm{~h}^{-1} \mathrm{e}$, na ausência de chuvas, foi ligado semanalmente por um período variável.

Os dados referentes à precipitação pluviométrica, temperaturas médias e irrigações realizadas durante o ciclo da soja na safra 2003/2004, assim como a época de ocorrência dos diferentes estádios fenológicos da soja, estão apresentados na Figura 1. Diante dessas

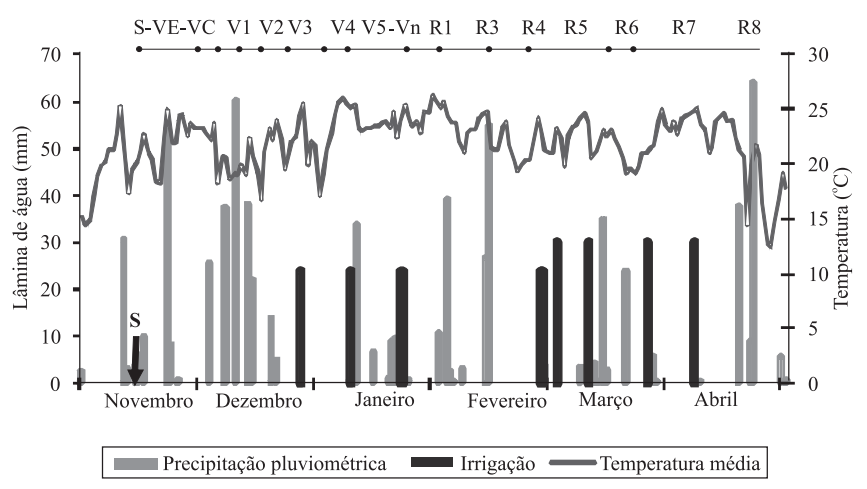

Figura 1. Data da semeadura (S), irrigações, precipitação pluviométrica, temperatura média diária, e estádios de desenvolvimento fenológico da soja (S-VE-VC a R8) no ano agrícola de 2003-2004. 
condições climáticas, as irrigações começaram a ser aplicadas ainda na fase vegetativa da cultura da soja, e estenderam-se até a maturação (estádio R8), totalizando $216 \mathrm{~mm}$ aplicados em oito irrigações, cinco delas coincidentes com o período crítico de desenvolvimento da soja.

Os dados foram submetidos à análise de variância, a 5\% de probabilidade e, quando houve significância para os tratamentos, as médias foram comparadas pelo teste de Tukey, a 5\% de probabilidade, dentro das condições irrigado e sem irrigação. $\mathrm{Na}$ ausência de significância para o fator doses de resíduos, as condições de tráfego, irrigação e profundidade teórica de atuação do sulcador foram comparadas pelo teste $\mathrm{t}$ de comparação de médias.

\section{Resultados e Discussão}

As doses de resíduo de aveia-preta não afetaram significativamente a FT, a FT específica e o volume de solo mobilizado pela haste sulcadora da semeadora, independentemente da sua profundidade de trabalho e da presença ou ausência de tráfego dos rodados do trator. Os valores da FT variaram de 648 a $1.200 \mathrm{~N}$, enquanto a FT específica oscilou entre 13 e $24 \mathrm{~N} \mathrm{~cm}^{-2}$ e o volume de solo mobilizado variou entre 120 e $171 \mathrm{~m}^{3} \mathrm{ha}^{-1}$ para as profundidades de 0,064 e $0,10 \mathrm{~m}$, respectivamente.

Com o aumento da profundidade de atuação do sulcador de 0,064 para $0,10 \mathrm{~m}$, houve incremento significativo na FT, da ordem de 100\% (Tabela 1), o que corrobora dados de Cepik et al. (2005), obtidos em trabalho realizado no mesmo Argissolo. Maiores valores de FT também foram obtidos para o local com tráfego, em comparação ao sem tráfego, o que

Tabela 1. Força de tração e força de tração específica na haste sulcadora da semeadora-adubadora de acordo com a profundidade de atuação da haste e da presença ou não de tráfego de rodados do trator ${ }^{(1)}$.

\begin{tabular}{lcc}
\hline Tratamentos & $\begin{array}{c}\text { Força de tração } \\
(\mathrm{N})\end{array}$ & $\begin{array}{c}\text { Força de tração } \\
\text { específica }\left(\mathrm{N} \mathrm{cm}^{-2}\right)\end{array}$ \\
\hline Profundidade da haste $(\mathrm{m})$ & & \\
0,064 & $649 \mathrm{~b}$ & $14,2 \mathrm{~b}$ \\
0,100 & $1.617 \mathrm{a}$ & $24,1 \mathrm{a}$ \\
\hline Tráfego & & \\
Sem & $769 \mathrm{~b}$ & $13,1 \mathrm{~b}$ \\
Com & $1.497 \mathrm{a}$ & $27,3 \mathrm{a}$ \\
\hline
\end{tabular}

${ }^{(1)}$ Médias seguidas de letras iguais, nas colunas dentro de cada tratamento, não diferem entre si pelo teste de Tukey, a 5\% de probabilidade. indica que o tráfego acumulado durante as safras anteriores causou uma compactação relativa no local de passagem dos pneus do trator. Da Rosa et al. (2008) também encontraram maior esforço de tração em hastes sulcadoras de semeadoras que atuaram em áreas com maior grau de compactação, caracterizadas por tempo maior após a realização de uma escarificação.

Os resultados obtidos para a FT específica, ou seja, a FT demandada na haste sulcadora relacionada à área da seção transversal do sulco mobilizado (Tabela 1), foram similares aos discutidos para a FT. No entanto, a diferença entre os valores das profundidades e entre os locais de atuação da haste em relação ao tráfego de rodados não foi tão expressiva como na FT. Isso significa que o aumento da profundidade de atuação do sulcador e da compactação do solo na linha de tráfego implicou aumento na área da seção transversal de solo mobilizado no sulco. Para confirmar essas afirmações, observou-se que o aumento da profundidade de atuação do sulcador de 0,064 para $0,10 \mathrm{~m}$ ocasionou um incremento de apenas $41 \%$ no volume de solo mobilizado no sulco, de 120 para $171 \mathrm{~m}^{3} \mathrm{ha}^{-1}$. No entanto, esse aumento de mobilização foi inferior ao encontrado por Cepik et al. (2005) em Argissolo na condição friável e, consequentemente, a FT específica determinada foi superior para as duas profundidades de atuação da haste sulcadora neste caso.

A produtividade de grãos de soja não foi influenciada pelos fatores dose de resíduos e profundidade de atuação do sulcador de adubo da semeadora-adubadora, quando na presença de irrigação suplementar (Tabela 1). No experimento não irrigado, houve diferença significativa na produtividade da soja em função do grau de mobilização do solo, ou seja, da profundidade de atuação do sulcador de adubo. Na média, houve um acréscimo significativo, de $180 \mathrm{~kg} \mathrm{ha}^{-1}$ de grãos (10\%), na maior profundidade de atuação do sulcador de adubo. Isso demonstra que o aumento da profundidade de atuação da haste sulcadora de 0,064 para $0,10 \mathrm{~m}$ foi uma estratégia viável para aumentar a produtividade da soja em condições de deficiência hídrica (Figura 1). De acordo com Debiasi (2008), o aumento da produtividade das culturas em função do uso de maiores profundidades de atuação da haste sulcadora de adubo, em condições de deficiências hídricas moderadas, pode ser atribuído ao rompimento localizado de camadas compactadas existentes na superfície do solo, o que aumenta a infiltração e o armazenamento de 
água disponível para as plantas no solo e favorece o desenvolvimento radicular das culturas. Além disso, a deposição do adubo em maiores profundidades pode estimular o crescimento das raízes em profundidade, tendo em vista que, em sistema de plantio direto, os nutrientes tendem a se concentrar na superfície do solo (Merten \& Mielniczuk, 1991). Neste trabalho, nos tratamentos não irrigados, verificou-se que a quantidade de raízes da soja tendeu a ser maior quando a haste sulcadora atuou na maior profundidade (Tabela 2), embora as diferenças não tenham sido estatisticamente significativas. Tal fato pode ter colaborado para que a soja apresentasse maior tolerância aos períodos de deficiência hídrica observados na safra 2003/2004 e aumentado, assim, a sua produtividade.

Verificou-se, ainda, que as doses de resíduos de aveia-preta na superfície do solo não influenciaram de modo significativo a produtividade da soja, mesmo no experimento não irrigado (Tabela 3). Esse resultado pode ser associado ao fato de que as deficiências hídricas mais importantes na safra de 2003/2004 ocorreram durante a fase reprodutiva da soja, quando o dossel vegetativo da cultura já cobria praticamente toda a superfície do solo.

Na média geral dos tratamentos, houve uma diferença significativa de $1.020 \mathrm{~kg} \mathrm{ha}^{-1}$ de grãos, em favor do experimento irrigado, em relação ao experimento sem irrigação suplementar (Tabela 3). A produtividade média de grãos no experimento irrigado foi de $2.960 \mathrm{~kg} \mathrm{ha}^{-1}$, compatível com o potencial de produção da cultivar, estimado em $3.031 \mathrm{~kg} \mathrm{ha}^{-1}$ (Bonato et a., 2001). No experimento sem irrigação, a produtividade

Tabela 2. Massa de matéria seca da parte aérea (MSPA), de grãos e de matéria seca de raízes (MSR) de soja, de acordo com diferentes profundidades de atuação do sulcador de adubo nos experimentos irrigado e não irrigado ${ }^{(1)}$.

\begin{tabular}{lccc}
\hline $\begin{array}{l}\text { Profundidade da haste } \\
(\mathrm{m})\end{array}$ & MSPA & $\begin{array}{c}\text { Grãos } \\
\text { Irrigado }\end{array}$ & MSR \\
\hline & ----------- \\
0,064 & 5,4 & 2,9 & 3,7 \\
0,100 & 5,7 & 3,0 & 3,7 \\
\hline Média & $5,55 \mathrm{~A}$ & $2,96 \mathrm{~A}$ & $3,70 \mathrm{~A}$ \\
\hline & & Não irrigado & \\
0,064 & $3,3 \mathrm{~b}$ & $1,8 \mathrm{~b}$ & $4,2 \mathrm{~b}$ \\
0,100 & $3,7 \mathrm{a}$ & $2,0 \mathrm{a}$ & $4,7 \mathrm{a}$ \\
\hline Média & $3,50 \mathrm{~B}$ & $1,94 \mathrm{~B}$ & $4,45 \mathrm{~A}$ \\
\hline
\end{tabular}

(1)Médias seguidas de letras iguais, minúsculas nas comparações entre profundidades e maiúsculas na comparação entre as condições de irrigação, não diferem entre si pelo teste de Tukey, a $5 \%$ de probabilidade. de grãos foi de $1.940 \mathrm{~kg} \mathrm{ha}^{-1}$, superior à obtida por Lunardi et al. (2008) na mesma safra e local.

A população final de plantas de soja na época da colheita foi de 199.000 e 194.000 plantas ha $^{-1}$, nas áreas irrigada e não irrigada, respectivamente, e a população final não foi afetada significativamente pelos tratamentos.

A quantidade de MSPA da soja, a exemplo da produtividade de grãos, também não foi influenciada pelos tratamentos profundidade do sulcador e doses de resíduos no experimento com irrigação. $\mathrm{Na}$ ausência de irrigação, houve diferença significativa de MSPA, da ordem de $480 \mathrm{~kg} \mathrm{ha}^{-1}$ (15\%), em favor da maior profundidade de atuação do sulcador de adubo (Tabela 2). Essa maior quantidade de matéria seca produzida é relevante do ponto de vista agronômico, pois adiciona matéria orgânica ao solo e possibilita a manutenção da sua cobertura, que previne a erosão hídrica, diminui a emergência de plantas daninhas e a amplitude térmica, e aumenta a conservação da umidade na superfície e no perfil do solo (Landers, 1995).

Assim como a produtividade de grãos de soja, os valores médios de MSPA foram maiores no experimento irrigado em relação ao experimento não irrigado (Tabela 2). Na média geral dos tratamentos, houve uma diferença de $2.040 \mathrm{~kg} \mathrm{ha}^{-1}$ de matéria seca da parte aérea (58\%) em favor do experimento com irrigação suplementar em relação ao experimento não irrigado. Essa diferença era esperada, pois as plantas de soja no experimento irrigado apresentavam uma estatura $0,22 \mathrm{~m}$ maior que no experimento não irrigado aos 90 dias após a semeadura (estádio R5). É fato que a maior produtividade de grãos está de certa forma relacionada a uma maior produtividade de MSPA, em

Tabela 3. Produtividade média de grãos de soja $\left(\mathrm{Mg} \mathrm{ha}^{-1}\right)$ nos experimentos irrigado e não irrigado, nos tratamentos $\operatorname{avaliados}^{(1)}$.

\begin{tabular}{lcccc}
\hline \multirow{2}{*}{$\begin{array}{c}\text { Doses de } \\
\text { resíduos } \\
\left(\mathrm{Mg} \mathrm{ha}^{-1}\right)\end{array}$} & \multicolumn{3}{c}{ Sem irrigação } & Irrigado \\
\cline { 2 - 3 } & \begin{tabular}{l} 
Profundidade efetiva do sulcador $(\mathrm{m})$ \\
\cline { 2 - 3 }
\end{tabular} & 0,064 & Média & \\
2 & 1,45 & 2,100 & 1,78 & 2,99 \\
3 & 1,75 & 1,81 & 1,78 & 3,25 \\
4 & 1,87 & 1,87 & 1,87 & 2,94 \\
5 & 1,68 & 2,02 & 1,85 & 2,74 \\
6 & 2,24 & 2,19 & 2,22 & 2,85 \\
\cline { 1 - 2 } Médias & 2,12 & 2,17 & 2,15 & 2,98 \\
\hline (1) Médias seguidas de letras iguais não diferem entre si pelo teste de Tukey, \\
a 5\% de probabilidade. CV resíduos, 22,8\%; CV profundidades, 11,9\%.
\end{tabular}


virtude de ser essa a fonte de compostos orgânicos. Essa relação pode ser observada comparando, nas médias gerais dos experimentos, as produções de MSPA com as produções de grãos de soja: para produzir $1 \mathrm{~kg}$ de grãos, foram necessários 1,88 e 1,81 kg de MSPA nos experimentos irrigado e não irrigado, respectivamente, valores semelhantes que demonstraram uma proporcionalidade na partição de fotoassimilados para a parte aérea da planta (grãos e parte vegetativa), independentemente das restrições ambientais.

A MSR da soja não apresentou diferenças significativas entre os experimentos com e sem irrigação. $\mathrm{O}$ experimento não irrigado apresentou, na média geral dos tratamentos, uma diferença de $770 \mathrm{~kg} \mathrm{ha-1}$ de raízes $(21 \%)$ a mais em relação ao experimento irrigado, apesar da menor produção de massa seca de parte aérea e de grãos. Isso é uma indicação de que, diante da menor disponibilidade de água, as plantas direcionam as reservas energéticas para a produção de raízes na tentativa de compensar essa adversidade por meio da exploração de um maior volume de solo (Beutler \& Centurion, 2004).

As doses de resíduos de aveia-preta dentro dos experimentos irrigado e não irrigado não influenciaram a produção da biomassa total da soja. Entretanto, houve produção de $2,3 \mathrm{Mg} \mathrm{ha}^{-1}$ a mais de biomassa no experimento irrigado, resultado da maior produção de grãos e de MSPA (Tabela 2). No experimento irrigado, não houve modificação na distribuição de matéria seca nos diferentes compartimentos da planta quando a profundidade de atuação do sulcador de adubo foi alterada de 0,064 para 0,100 m, diferentemente do que ocorreu no experimento não irrigado, no qual houve maior produção de grãos, MSPA e MSR (Tabela 2) quando a profundidade de atuação do sulcador de adubo foi de $0,100 \mathrm{~m}$.

Da biomassa total produzida pela cultura da soja, 45, 24 e 31\% corresponderam à massa de matéria seca da parte aérea, de grãos e de raízes até a profundidade de $0,12 \mathrm{~m}$, respectivamente, na média dos tratamentos com irrigação. No experimento sem irrigação, essa distribuição foi alterada para 35, 20 e $45 \%$, respectivamente, o que indica que, na falta de umidade adequada para o seu desenvolvimento, a cultura priorizou a produção de raízes em detrimento da produção de grãos e MSPA. Herzog et al. (2004) constataram que, da biomassa total produzida pela soja, 38, 28 e 34\% eram de grãos, MSPA e MSR até a profundidade de $0,15 \mathrm{~m}$, respectivamente, na média dos tratamentos com e sem irrigação.

As doses de resíduos e a profundidade de sulcamento não influenciaram o IC nos experimentos com e sem irrigação e apresentaram valores semelhantes na média, o que demonstra que a deficiência de água no experimento sem irrigação não influenciou a eficiência de translocação dos produtos da fotossíntese para os grãos em comparação com o experimento irrigado, apesar das produtividades distintas. Thomas \& Costa (1994) observaram que a deficiência hídrica promoveu um IC mais elevado nas plantas de soja no tratamento irrigado em relação ao verificado nas plantas do tratamento sem irrigação. Peixoto et al. (2000) encontraram diferenças no IC em variedades de soja submetidas à deficiência hídrica em três fases fenológicas da planta e concluíram que as cultivares estudadas tinham sensibilidade diferenciada à deficiência hídrica nas diversas fases fenológicas.

Para a massa de 1.000 grãos, foi determinada somente a média geral em cada experimento, que correspondeu a 198,9 g (tratamento irrigado) e $183,9 \mathrm{~g}$ (tratamento sem irrigação), ou seja, uma diferença de $8 \%$ em favor do experimento com irrigação. O número médio de legumes por planta de soja não diferiu entre os tratamentos profundidade de sulcamento e doses de resíduos nos experimentos irrigado e não irrigado. Na média geral dos tratamentos profundidade do sulcador e doses de resíduos, o experimento com irrigação complementar apresentou 37,3 legumes por planta, contra 26,7 na área não irrigada. No experimento não irrigado, deficiências hídricas ocorridas no período crítico que se estendeu do início do florescimento ao enchimento de grãos (Figura 1) resultaram em menor altura de plantas de soja aos 90 dias após a semeadura, bem como restringiram a produção de matéria seca da parte aérea, o número de legumes por planta e a massa de 1.000 grãos e, em consequência disso, reduziram a produtividade de grãos de soja. Thomas \& Costa (1994) observaram que as plantas de soja conduzidas sob irrigação apresentaram maior número de legumes, enquanto o número de legumes do tratamento não irrigado foi afetado pelo menor crescimento vegetativo das plantas. Heiffig (2002) concluiu que o número de legumes por planta é o mais importante dos componentes de rendimento, por ser diretamente influenciado pelo arranjo das plantas na área de produção. Segundo Beutler et al. (2005), 
níveis crescentes de compactação resultaram em redução na altura das plantas, na massa seca da parte aérea, no número de legumes por planta e na massa de 1.000 grãos da soja. Na média geral dos experimentos, o número médio de grãos de soja por legume $(2,1)$ não diferiu, o que indica que esse componente de rendimento não foi afetado pela irrigação suplementar. Heiffig (2002) e Rambo et al. (2002) observaram que o número de grãos de soja por legume não foi alterado em função do arranjo de plantas, assim como Thomas \& Costa (1994), trabalhando em condições similares. Tanto o número de grãos por legume quanto o peso do grão têm controle genético substancial e, por isso, têm pequena variação (Rambo et al., 2003).

\section{Conclusões}

1. As quantidades de resíduo cultural de aveia-preta na superfície do solo não influenciam a força de tração, a força de tração específica e o volume de solo mobilizado pelas hastes sulcadoras.

2. A maior profundidade do sulco de semeadura e a localização do sulco sob o tráfego dos rodados do trator demandam maior força de tração e força de tração específica.

3. O aumento da profundidade de atuação das hastes sulcadoras de adubo das semeadoras-adubadoras mostrou-se uma estratégia viável para aumentar a produtividade da soja em condições de deficiência hídrica.

\section{Agradecimentos}

À Estação Experimental da Universidade Federal do Rio Grande do Sul, pela infra-estrutura disponibilizada para a realização do experimento, e ao Conselho Nacional de Desenvolvimento Científico e Tecnológico, pela concessão de bolsa de estudo.

\section{Referências}

AMERICAN SOCIETY OF AGRICULTURAL ENGINEERS. Agricultural machinery management data. In: AMERICAN SOCIETY OF AGRICULTURAL ENGINEERS. ASAE standards 1999: standards engineering practices data. Saint Joseph: ASAE, 1999. p.359-366.

ARATANI, R.G.; MARIA, I.C. de; CASTRO, O.M. de; PECHE FILHO, A.; DUARTE, A.P.; KANTHACK, R.A.D. Desempenho de semeadoras-adubadoras de soja em Latossolo Vermelho muito argiloso com palha intacta de milho. Revista Brasileira de Engenharia Agrícola e Ambiental, v.10, p.517-522, 2006.
BERGAMASCHI, H.; GUADAGNIN, M.R.; CARDOSO, L.S.; SILVA, M.I.G. Clima da Estação Experimental da UFRGS (e região de abrangência). Porto Alegre: UFRGS, 2003. 78p.

BEUTLER, A.N.; CENTURION, J.F. Compactação do solo no desenvolvimento radicular e na produtividade da soja. Pesquisa Agropecuária Brasileira, v.39, p.581-588, 2004.

BEUTler, A.N.; CENTURION, J.F.; SILVA, A.P. da. Soil resistance to penetration and least limiting water range for soybean yield in a haplustox from Brazil. Brazilian Archives of Biology and Technology, v.48, p.863-871, 2005.

BONATO, E.R. Estresses em soja. Passo Fundo: Embrapa Trigo, 2000. 254p.

BONATO, E.R.; BERTAGNOLLI, P.F.; LINHARES, A.G.; COSTAMILAN, L.M.; KIIHL, R.A. de S.; ALMEIDA, L.A. BRS 137: cultivar de soja para cultivo no Sul do Brasil. Pesquisa Agropecuária Brasileira, v.36, p.841-843, 2001.

CEPIK, C.T.C.; TREIN, C.R.; LEVIEN, R. Força de tração e volume de solo mobilizado por haste sulcadora em semeadura direta sobre o campo nativo, em função do teor de água no solo, profundidade e velocidade de operação. Engenharia Agrícola, v.25, p.447-457, 2005.

DA ROSA, D.P.; REICHERT, J.M.; SATTLER, A.; REINERT, D.J.; MENTGES, M.I.; VIEIRA, D.A. Relação entre solo e haste sulcadora de semeadora em Latossolo escarificado em diferentes épocas. Pesquisa Agropecuária Brasileira, v.43, p.395-400, 2008.

DEBIASI, H. Recuperação física de um Argissolo compactado e suas implicações sobre o sistema solo-máquina-planta. 2008. 263p. Tese (Doutorado) - Universidade Federal do Rio Grande do Sul, Porto Alegre.

DESCLAUX, D.; HUYNH, T.T.; ROUMET, P. Identification of soybean plant characteristics that indicate the timing of drought stress. Crop Science, v.40, p.716-722, 2000.

HEIFFIG, L.S. Plasticidade da cultura da soja (Glicine max (L.) Merrill) em diferentes arranjos espaciais. 2002. 85p. Dissertação (Mestrado) - Escola Superior de Agricultura "Luiz de Queiroz", Piracicaba.

HERZOG, R.L. da S.; LEVIEN, R.; TREIN, C.R. Produtividade de soja em semeadura direta influenciada por profundidade do sulcador de adubo e doses de resíduo em sistema irrigado e não irrigado. Engenharia Agrícola, v.24, p.771-780, 2004.

KOAKOSKI, A.; SOUZA, C.M.A. de; RAFULL, L.Z.L.; SOUZA, L.C.F. de; REIS, E.F. dos. Desempenho de semeadora-adubadora utilizando-se dois mecanismos rompedores e três pressões da roda compactadora. Pesquisa Agropecuária Brasileira, v.42, p.725-731, 2007.

LANDERS, J.N. Fascículo de experiências de plantio direto no cerrado. Goiânia: Associação de Plantio Direto no Cerrado, 1995. $261 \mathrm{p}$.

LUNARDI, R.; CARVALHO, P.C. de F.; TREIN, C.R.; COSTA, J.A.; CAUDURO, G.F.; BARBOSA, C.M.P.; AGUINAGA, A.A.Q. Rendimento de soja em sistema de integração lavoura-pecuária: efeito de métodos e intensidades de pastejo. Ciência Rural, v.38, p.795-801, 2008 . 
MELLO, L.M.M.; PINTO, E.R.; YANO, É.H. Distribuição de sementes e produtividade de grãos da cultura do milho em função da velocidade de semeadura e tipos de dosadores. Engenharia Agrícola, v.23, p.563-567, 2003.

MERTEN, G.H.; MIELNICZUK, J. Distribuição do sistema radicular e dos nutrientes em Latossolo Roxo sob dois sistemas de preparo do solo. Revista Brasileira de Ciência do Solo, v.15, p.369-374, 1991.

NEUMAIER, N.; NEPOMUCENO, A.L.; FARIAS, J.R.B.; OYA, T. Estresses de ordem ecofisiológica. In: BONATO, E.R. (Ed.). Estresses em soja. Passo Fundo: Embrapa Trigo, 2000. 254p.

PEIXOTO, C.P.; CÂMARA, G.M. de S.; MARTINS, M.C.; MARCHIORI, L.F.S.; GUERZONI, R.A.; MATTIAZZI, P. Época de semeadura e densidade de plantas de soja: I. Componentes da produção e rendimento de grãos. Scientia Agrícola, v.57, p.89-96, 2000.

RAMBO, L.; COSTA, J.A.; PIRES, J.L.F.; PARCIANELLO, G.; FERREIRA, F.G. Rendimento de grãos da soja e seus componentes por estrato do dossel em função do arranjo de plantas e regime hídrico. Scientia Agraria, v.3, p.79-85, 2002.
RAMBO, L.; COSTA, J.A.; PIRES, J.L.F.; PARCIANELLO, G.; FERREIRA, F.G. Rendimento de grãos da soja em função do arranjo de plantas. Ciência Rural, v.33, p.405-411, 2003.

SCHULER, R.T.; WOOD, R.K. Soil compaction. In: CONSERVATION tillage systems and management: crop residue management with no-till, ridge-till, mulch-till. Ames: Midwest Plan Service, 1992. p.42-45.

SILVA, V.R.; REINERT, D.J.; REICHERT, J.M. Densidade do solo, atributos químicos e sistema radicular do milho afetados pelo pastejo e manejo do solo. Revista Brasileira de Ciência do Solo, v.24, p.191-199, 2000.

SOCIEDADE BRASILEIRA DE CIÊNCIA DO SOLO. Comissão de Química e Fertilidade do Solo RS/SC. Manual de adubação e calagem para os Estados do Rio Grande do Sul e Santa Catarina. 10.ed. Porto Alegre: Sociedade Brasileira de Ciência do Solo, 2004. 394p.

THOMAS, A.L.; COSTA, J.A. Influência do déficit hídrico sobre o desenvolvimento e rendimento da soja. Pesquisa Agropecuária Brasileira, v.29, p.1389-1396, 1994.

Recebido em 16 de fevereiro de 2009 e aprovado em 4 de agosto de 2009 